\title{
The Economics of Educational Planning: The Nigerian Challenge
}

\author{
Obasi K. Kenneth and Osah O. Sarah
}

\section{ABSTRACT}

\begin{abstract}
An increase in demand for educational services and the rising cost of satisfying the demand with the scarce resources available is a major justification for introducing economics in educational planning. This paper examined the economics of educational planning and the challenges faced by Nigerian educational planners. It looked at the concept of educational planning and the basis for introducing economics into educational planning. It also discussed economic concepts like demand for educational services, cost-benefit analysis, cost-effectiveness and the budgeting process. The challenges of the economics of educational planning were also discussed. The challenges identified include no institutional framework for labour market information to aid planners, inadequate statistics on the way people earn according to educational levels and other sources of income amongst others. It was suggested among other things that there should be a national institutional mechanism/framework to handle labour market information. Also, the Federal Ministry of Education, in alliance with the National Bureau of Statistics should develop a strategic plan that will have the computing and provision of economic data necessary for educational planning as its focal point.
\end{abstract}

Keywords: Analysis, Cost-Benefit, Cost Effectiveness, Educational Planning.

\section{INTRODUCTION}

Education is a key driver for economic growth and development. It is a veritable instrument for national transformation and advancement. The global race of the $21^{\text {st }}$ century which has acted as a developmental catalyst for many countries while many others are struggling in playing catch up has placed education and its planning in the spotlight. Hence, the educational global race is significantly impacting and shaping nations both positively and otherwise. In modern times when the focus is on the 'knowledge economy, the role of education becomes all the more important in a nation's development. No country can attain sustainable economic development without significant investment in its human capital.

Education is a structured method, through which a nation builds up its human capital by supplying them with appropriate knowledge, skills, attitudes, and values for an effective drive of the social institutions of a given country. The role to be played by education in a society is multidimensional. It is anticipated to mould the learner's character, to enlighten him on things that are value-laden and socially desirable. It is an instrument for economic empowerment through the acquisition of relevant skills, knowledge and attitudes. Education, therefore, is a critical component for
Published Online: September 27, 2021

ISSN: $2736-4534$

DOI: 10.24018 / ejedu.2021.2.5.145

K. K. Obasi*

Department of Educational Management, Faculty of Education, University of Port Harcourt, Rivers State, Nigeria.

(e-mail: padrekenkel@ ${ }^{\circledR}$ ahoo.com)

\section{O. S. Sarah}

Department of Educational Management, Faculty of Education, University of Port Harcourt, Rivers State, Nigeria.

(e-mail: sarahosah@yahoo.com)

*Corresponding Author personal improvement and social transformation and advancement. It ensures quality human capacity development. Education, therefore, is a social as well as an invaluable social investment. Ipso facto, to ensure the realization of these very essential goals of economic and social development and transformation, educational systems and programmes need to be effectively planned [1].

Educational planning is a process that involves deciding in advance the educational policies and programmes that will lead to the achievement of pre-determined goals. It is an integral process in the management of educational systems worldwide. Educational planning is a process that involves the utilization of judicious and orderly surveys for the benefit of educational development and improvement to enhance education to be more successful and proficient in reacting to the necessities and objectives of individuals and society. It is a process that facilitates the optimization of scarce resources, prioritizes educational goals and objectives to guarantee socio-economic growth and development [1]. Educational planning targets at ensuring that all strata of the system of education are harmonized, increase in quantity, quality and also facilitates overall development. It guarantees the development of skilled manpower which serves in all the other sectors of the economy. The continued global economic downturn that has exacerbated the economic crisis in both the developed and less developed economies has placed a 
compelling emphasis on the economics of educational planning.

Economics is a body of knowledge that is systematically organized on the allocation of resources that are in high demand, but with a quantity or amount that are not enough to go round among alternative uses. Because it deals with the allocation of sparse resources, economic considerations are now to a great extent being used in many phases of the process of educational planning. Economics introduces an element of efficiency into the educational planning process. Narrowly defined, efficiency in education refers to using the least amount of input to achieve the stated objectives. The introduction of economic methods to educational planning goes a long way to cut down on wastage of time and resources and paves the way for the maximization of resources. Hence this paper looks at the application of the economic concepts of demand, cost, and budgeting to educational planning in Nigeria.

\section{ECONOMICS OF EDUCATIONAL PLANNING}

Planning is a basic management function. It is a process that involves setting up priorities for future courses of action to achieve stated goals and objectives. Planning as a process involves the development of goals, strategies, task lists and schedules to achieve the objectives of an organization. It is an essential function of management and is meant to achieve the highest degree of need satisfaction, based on resources available. As a process, it specifies the goals and objectives to be realized, maps out strategies to achieve them, sets out or devices the means required, implements, directs, monitors all steps accordingly [2] and brings a solution to economic problems that ensue from the scarcity of resources. The planning activity is borne out of the realization of scarcity or limited resources at the disposal of a person or a nation. Alabi and Okemakinde [3] conceptualized planning as a process of gathering data and systematically using them to project future development about specific estimates of resources needed to achieve proposed development. It spells out the course of action concerning objectives, cost, time frame, sources of funds and how the goals will be achieved. Planning is futuristic, systematic, rational and done to achieve a goal. Educational planning is an aspect of planning that strives to research, develop, implement and advance programs and reforms within the education sector. It could be both key and functional that explains the plans, assets (human and material), that ensure the successful and productive use of supplies in the acknowledgement of expressed aim and purposes. Educational planning is the domestication of planning within the domain of the education process. It is an administration capacity and apparatus that attempts to comprehend the present educational difficulties, issues, shortcomings and qualities, to project into the future, the awareness of the dynamic nature of the environment, so that education systems can be compelling, productive, practical, reliable and highly rated. Educational planning along these lines overcomes any issues between the present and future educational requirements occasioned by the dynamic demands of the environment, both external and internal [4]. It is a continuous process directed towards ensuring the provision of adequate educational services to achieve increased growth and development. It is a process of preparing a set of decisions as it relates to the education sector for future action. Ololube [5] explained that educational planning is a process through which a set of decisions about educational enterprise is prepared to ensure that the goals and purposes of education will be greatly achieved in the future with the resources in place. Similarly, Butt, Hussain and Rehman [6] stated that educational planning is the way toward setting out ahead of time; methodologies, strategies, systems, projects and principles through which a set of educational goals and objectives can be achieved.

Educational planning significantly guarantees that all decisions about the educational system are based on factual evidence to make the system address the needs of the people as well as that of the economy. To a very large extent, this is where educational planning exhibits its umbilical relationship with economics. It is an activity of forethought that leads to the assurance of strategy, needs and expenses of an educational framework, taken comprehension of the monetary and political real factors for the framework's latent capacity and development, and the necessities of the nation and the tutees served by the framework. The process takes decisions that will affect the development of a nation in its socio-cultural, political and economic spheres in the future [7]. Educational planning is, therefore, a binding force that coordinates and directs the different levels of an education system and ensures that widely accepted long-term goals are approached more objectively. It implies a realistic appraisal of a country's financial means, its human resources and institutional structures and other factors, bearing upon the success of an educational plan in 1964. Barely any aspect of educational planning is discussed without inputs from economic science.

Economics of educational planning involves the planning of education with an economic mirror. It entails relating costs of education to financial and materials resources and needs. Economic components such as demand, cost, funding, productivity and budgeting are integral aspects of the educational planning process. Economics is relevant to educational planners who have the task of ensuring that the unlimited demands of the education sector are met. It helps the planners to understand the concepts of quality and equity and how to apply them. It makes the planner cautious, resourceful and effective and efficient in the distribution, allocation, utilization of educational resources. The understanding of how the education system reacts to the labour market about the different areas of specialization and the employment opportunities for occupational choices are all issues related to the economics of educational planning. The economics of educational planning is beginning to gain momentum in recent times in the provision of education. 1

The very essence of the economics of educational planning is constantly reinforced by the increase in the demand for educational services and the rising cost of education amidst the continuous dwindling of scarce resources. To that extent, Wheeler [8] remarked that an unlimited resource is not economically significant. Restriction to its use is of no use because there is no limited supply available for the second option of use on which to subject the amount saved. Hence, initial savings could not accrue any benefit. On the other 
hand, the limited resources are significantly economic because usage of one scarce resource more often leads to less devotion of attention to the usage of other resources. Ipso facto, educational planning as a discipline, was before now an integral part of the economics of education and educational planning was meant to be used as an instrument for ensuring that educational provision was properly guided by positive economics in the face of limited resources. It is all about efficiency in resource utilization. To that extent, Obasi [4] aptly remarked that as a critical factor in national development and social engineering, the provision of education cannot safely be left to chance or be an easy tool for cheap political goals at the expense of national security and development.

The application of the principles of economics remains sacrosanct if education systems are to be truly committed to national development. Babalola [9] corroborated this position when he pointed out that economics of education, as the study of human behaviour and schooling, deals with how this behaviour affects economic growth and development. It deals with the study of economic issues relating to education and bits of knowledge acquired from theory and empirical findings of economics to settle on better choices and tackle genuine issues. It includes the utilization of monetary terms, ideas, standards and laws during the time spent creating, financing, disseminating and adapting educational products and services. The majority of contemporary crises in education are either economic or financial. Thus, the economic environment within which they operate immediately affects schools. In the end, schools affect the economic environment itself. Consequently, education practitioners require an economic analysis in answering educational questions. When these realities are either strange to or ignored by the education system, the negative consequences are colossal.

The staggering high level of unemployment among graduates in the face of manpower shortages in some critical sectors of the economy is a case in point. Again, there is an obvious inverse relationship between skills demand and supply, with a large estimate of skills mismatch. It is therefore imperative to harmonize the demand and supply of manpower with appropriate economic approaches. The issue of curriculum relevance makes the adoption of economics to the educational planning process is imperative. The labour market is intensively knowledge-based and technologydriven. It is no secret among the critical stakeholders in education that the curriculum contents need to be reviewed in line with the realities of the time. The increase in the politicization of education provision at the expense of the application of positive economics in the planning of education is a source of concern that requires urgent attention. The allocation of educational resources based on political convenience has resulted in the uncoordinated expansion of the education system in many countries. Hence there is a need for the application of economics to educational planning.

\section{THE DEMAND FOR EDUCATION AND THE ECONOMY}

The need for an education service based on demand analysis is the first step to be considered in the economic justification of educational planning. Demand for education is expressed by the total number of persons desiring to acquire a given level or type of education at a particular time. To identify the demand, maximize the relevance and impact of educational activity, it is important to carry out a needs assessment that is comprehensive and relevant to the challenges confronting the people. Without need assessment, educational planning is unlikely to be effective. When adequate educational needs assessments of the target audience are conducted and planning is linked to practice, education is more likely to engage the citizens and achieve stated objectives [10].

Educational planning in Nigeria with regards to need assessments and demand analysis has seen improvements, development, innovations, adjustments and changes over the years. The Ashby Commission of 1959, for instance, was set up to carry out an extensive assessment of Nigerian higher education to the manpower needs of the economy. At that time, the country was in dire need of the required manpower to take over the government jobs being vacated by expatriates. The mandate of the commission was to investigate the needs of Nigerian higher education within the timeframe of 20 years. A major recommendation from the commission was to set up a post-secondary education system as the prime objective, to produce before 1970 high-level manpower in good quantity which the nation was in dear need of. The flow should be designed in the instance that it could be pronounced, for it not to be re-planned, to take care of the Nigerian needs up to 1980 . However, according to Alao [11], the curriculum content of the Nigerian education system after the recommendations of the commission were seen as supporting and churning out job-seeking elites who were scavenging white-collar jobs instead of assisting in developing self-reliant people who would contribute meaningfully to the development of their nation.

The recommendations made during the 1969 National Conference on Curriculum Development led to the formation of the National Policy on Education (NPE) of 1977. The policy advocated a 6-3-3-4 system acquisition of knowledge and skills. In 1999 the Universal Basic Education Programme was established after series of needs assessments. The outcomes of the Universal Basic Education Program further led to the consolidation of a new Senior Secondary Education Curriculum (SSEC) which the Nigerian Educational Research and Development Council (NERDC) developed and launched in 2011.

The intention for SSEC was to meet national and global goals as well as bridge the gaps in the enactment of content and the delivery processes of the curriculum of secondary education and to make it relevant to the needs of society. These educational plans were developed in a bid to make the education system in Nigerian more functional and relevant to the needs of the economy. However, research findings show that the Nigerian education system has grossly fallen short of its goals.

Recent evidence according to the National Bureau of Statistics (NBS) [12] employment surveys plainly showed that the needs of the labour market are focusing more on knowledge and technology-driven skills in the different sectors. For instance, NBS [12] Q1 Employment Report revealed that job vacancies in Nigeria were concentrated in 
three sectors, in the following order: Trade and Services, Consulting, and Information and Communications Technology (ICT)/Telecommunications. The previously mentioned areas represented $79 \%, 4.7 \%$, and $2.5 \%$ of the absolute number of the advertised openings for jobs, separately. In the examination, essential areas, for example, Agriculture and Oil and Gas/Mining represented just 0.1\% and $0.7 \%$ of the opportunities accessible. However, an investigation of the number of applications for employment per opening in every area showed that Trade/Services got the most un-number of applications for employment while the Oil and Gas/Mining area got the most. This clearly shows a mismatch in the demand and supply of skills to the labour market which has resulted in a high unemployment rate. This high unemployment rate is mostly driven by the increased demand for cognitive and psychomotor skills which is largely needed in the trade, services and consulting sectors.

Different surveys on the demand of finesse in the labour market and the performance assessment employees who are graduates by employers across government-owned and private establishments in Nigeria showed a conspicuous detach between the work abilities procured by employees from educational establishments and the valuable aptitude and capability expected to execute errands in the labour market. Albeit the utilization of psychological abilities in Nigeria is developing, accessible proof, in any case, recommends that the cycle of production is as yet overwhelmed by the work of manual abilities [13]. Considering Nigeria's shift to an economy dominated by service, it is vital to take cognizant of the fact that these work abilities, which are to a great extent missing, are the ones demanded by the labour market. The ideal is that a change in the demand for skills by different sectors of the economy should bring about a corresponding change in the curriculum and educational plans.

Lack of institutional framework for labour market information (LMI) is a major challenge to educational planning in Nigeria. For instance, educational institutions required information on labour market trends, skill requirements needed in the economy, technological changes and programmes needed by (competing) institutions, to be able to develop and run relevant curriculum efficiently. The National Manpower Board (NMB) became a statutory body in 1991 and was inaugurated by the Federal Government of Nigeria in October 1992 specifically to gather, process, analyze and deploy information from the labour market to help in the policy formulation and strategic planning. The Federal Government in 2006, authorized the amalgamation of the NMB and the Nigerian Institute of Social and Economic Research (NISER) while retaining the name and functions of NISER. The range of responsibilities of NISER is wider than the labour market information. Since then, there is only small scale and statistically unreliable surveys undertaken. This could lead to a deduction that Nigeria has no institutional framework dedicated to the collection, collation, analysis, interpretation and dissemination of labour market information.

\section{ANALYSIS OF COST-BENEFIT IN EDUCATIONAL PLANNING}

Cost-benefit is an investment decision-making tool otherwise known as Rate of return analysis on investment. As an investment decision tool, it guides individuals and organizations on the best possible ways to deploy scarce resources to ensure the maximization of possible benefits Analysis of cost-benefit is the process that compares the projected or estimated costs and benefits (or opportunities) connected with the project decision to ascertain whether it is sensible from a business perspective. It involves tallying the costs of a project or decision and subtracting that amount from the total projected benefits of the project or decision.

Consequently, if the projected benefits are more than the cost, you could deduct that the decision is a good one to make. However, on the contrary, if the costs are more than the benefits, then the organization may have a second thought on the decision or project. It is a data-driven decision-making process [4]. Most models of analysis of cost-benefit usually factor the opportunity cost into the decision-making process. Opportunity costs are alternative benefits that could have been realized when choosing one alternative over another. In other words, the opportunity cost is the forgone or missed opportunity as a result of a choice or decision.

Factoring in opportunity costs allows managers or decision-makers to weigh the benefits from alternative courses of action and not merely the current path of choice being considered in the analysis of cost-benefit [14]. When the process is adequately carried out, cost-benefit analyses yield results that can lead to the development of reasonable conclusions about the feasibility and/or advisability of a decision or situation. Ipso facto, analysis of cost-benefit is relied upon by organizations in decision making because it presents issues evaluated in an agnostic and evidence-based way without being influenced by opinion, politics or bias. Its provision of a clear view of the consequences of a decision analyzes cost-benefit an indispensable tool in developing a business strategy or making resource allocation decisions.

In various disciplines, the analysis of cost-benefit has remained the foundation of the process of decision-making. In business, government, finance and even the non-profit world, analysis of cost-benefit uniquely and valuably provides insight into the decision of pursuing a proposed project or not, as it weighs investment opportunities, measure the social benefits, appraises the desirability of suggested policies, assesses change initiatives and so on [15]. Education as an economic good and an investment, though with some peculiarities, requires to a very large extent the application of analysis of cost-benefit in its planning to ensure some level of efficiency in the utilization of scarce resources. Hence, the technique is adopted by educational planners to analyse and rationalize decisions, policies and projects to make sure that education effectively and efficiently responds to individual and societal needs.

The detailed examination of the elements of cost-benefit of education, as a rule, comprises of actions to gauge the social or private investment return rate on any given kind of or level of education. The social return rate estimates the relationship between the before-charge lifetime income differentials related to a given education, and the total social expense of that education estimated as far as the opportunity cost this 
return rate can measure up to the pace of return on different kinds or levels of education, or with elective types of social speculation, to give a proportion of the monetary benefit of expenditure on education by the state [16]. Globally, education is described as one form of investment that accrues economic benefits to the recipient as well as to the society at large. However, the question is: how does investment in education compare with the benefits or returns? Responding to this question, Woodhall [16] stated that because analysis of cost-benefit is a financial specialist's instrument intended to reveal a monetary assessment of a venture plausibility.

Consequently, the use of analysis of cost-benefit to education centres unequivocally around the monetary benefits of education. Despite the contentions of certain researchers on how pertinent analysis of cost-benefit is to the planning of education, it ought to be commented that whenever it is perceived that interest in education produces critical monetary benefits, the need to dissect the nature and greatness of these benefits according to costs should likewise be perceived, even though this focuses on just piece of the complete picture. The device is expected to focus on certain critical components in the educational or economic arrangement of a nation, to wit; relative costs of various degrees of education and relative income of various classes of labour. Along these lines, regardless of the way that analysis of cost-benefit does not seem to frequently provide planners with orders of vivid strategy, it avails them the information necessary for making national policy decisions. Analysis of cost-benefit is an indispensable economic approach to educational planning, especially in this present time of harsh economic downturn. Analysis of cost-benefit or rate-of-return analysis is a means of assessing the benefits of a project in light of the costs that must be incurred. According to Izuagba [17] analysis of cost-benefit is defined as "the systematic comparison of the magnitude of costs versus benefits of any form of investment in education". This implies weighing the returns against the costs in a project. It helps to direct educational planners to consider the cost implications of innovation.

The cost-benefit analysis enables educational planners to analyze programme alternatives which lead to better and efficient plans. It could lead to changing resource allocation, in favour of the education types that offer the highest economic benefits. It helps in suggesting ways that could increase the profitability of education, which include increasing its benefits or lowering costs. Another merit of using analysis of cost-benefit is that it permits decentralized decision making. It assists planners to evaluate programmes and policies that are more measurable and quantifiable in monetary terms. The above shows that analysis of costbenefit focuses very strongly on the economic benefits of education. Ebong [18] observed that some educationists have argued that analysis of cost-benefit does not apply to education because educational objectives vary and there are other non-economic benefits. However, once it is acknowledged that educational expenditure is an investment that produces considerable economic benefits, the need to analyze the extent of these benefits concerning costs must also be acknowledged. Regarding how important planners in the less developed countries like Nigeria see the maximization of the goal of economic development, it is still necessary that some means with which to appraise the economic impact of education be put in place.

In computing the costs and benefits of a project, some basic assumptions as stated by Nelson [19] are made. The assumptions include; (a) all costs of a project can be determined and quantified in monetary terms, (b) all benefits of a project can be determined, assessed, measured and quantified in monetary terms and (c) all the benefits and costs of the project can be related and the net benefit determined. The vital components of an analysis of cost-benefit are a computation of the costs and benefits of an investment project and an appropriate rate of interest. The information is therefore summarized to compare it with the alternative investments' costs and benefits. Ihekweme [20] listed three basic ways of presenting this information: calculation of the present net value of the project, benefit-cost ratio and calculating the internal rate of return of the investment.

One of the challenges to the use of analysis of cost-benefit in the planning of education in Nigeria is in the assessment of costs. Preliminary estimates of costs are determined but they are either overestimated or underestimated. This situation is compounded by the gross dearth of reliable statistical data, poor data management, which is an unquantifiable impediment to planning. Instability in prices, shortage of raw materials and difficulties in foreign exchange are great impediments to accurate cost assessment. So many projects have been started hastily that it is not possible to assess their viability. For instance, the Universal Primary Education programme was introduced in the Western region by 1955 and the Eastern region by 1957 . The programme in these regions did not continue for up to a decade. Achuonye [21] reported that the Universal Primary Education programme of both regions was marred with serious problems associated with poor planning. The government underestimated the number of children, number of teachers, infrastructures and other financial implications of the programme. In the same vein, Alabekee and Ugwumba [22] observed that the Universal Primary Education Programme of 1976 failed to achieve the objectives for which it was set up because of several unanticipated problems associated with costs. Assessing the costs of an educational project is best carried out by experts in the field. Without such specialized knowledge, educational planning will fail to yield the desired results.

Another challenge to the use of analysis of cost-benefit in the planning of education is in estimating the future benefits. Doing the estimation of investment in education requires that consideration of expected input to future levels of output of education should be taken cognizance of. Education imparts skills and knowledge which thus lead to improved productivity of labour. Productivity of educated workers will have its reflection in increased output and earnings of higher nature. A gauge of the additional lifetime income of educated workers will be expected to get the benefits. These data can be assembled when the profit of educated and uneducated workers is looked at over their entire working lives. Lamentably, numerous nations including Nigeria do not have time-series data on the samples of educated and less-educated workers income. Ebong [18] expressed that cross-sectional data are utilized in the place of ascertaining the normal ageeducation-profit profiles for workers with various degrees of 
education. This is to say that instead of utilizing data to have workers sampled over their entire working lives, data are utilized to have workers sampled by their ages, collated at a single interval. The utilization of time-series data presents the undeniable degree of data legitimacy and accuracy that crosssectional data may not give.

The errand of acquiring data is perhaps the greatest obstacle in planning education in Nigeria and other nations that are yet developed. As per Woodhall [16], the accompanying rundown addresses data necessities in ideal conditions for cost-benefit analysis: (a) data on the profit of a delegate test of workers ordered by age, educational level, including type just as the length of tutoring, occupation, sex, social foundation, area of business, and some proportion of inherent capacity, for example, scores in an insight test; (b) data on the current use of educational organizations, by level; (c) appraisals of the capital worth of educational structures and hardware, by level; (d) assessments of private use on charges, books, writing material, and so forth, by level; (e)public consumption on grants, by level; (f) normal personal expense rates; ( $g$ ) data on work economic situations, including paces of joblessness and workforce interest, by age, sex and educational level. These necessities are ailing in Nigeria and the accessible ones are problematic because they are laden with controls. Ipso facto, to apply the cost-benefit analysis in the planning of education framework in Nigerian remaining parts a titanic undertaking.

\section{Cost Viability In EdUCATIONAL PlanNing}

Cost-viability analysis or cost-effectiveness analysis is a financial instrument for estimating the relationship between the overall contributions of a task and its yields. Both costviability analysis and cost-benefit analysis address monetary assessments of elective asset use and measure costs and benefits. In any case, cost-benefit analysis is utilized to decide just those sorts of ventures where the yield can be estimated in financial or monetary terms. The cost-viability analysis is intended to consider choice on options whereby the costs and results are taken into account in an orderly manner. This instrument is in a cozy relationship with cost-benefit analysis in the sense that both of them address financial assessments of the utilization of elective assets and measure cost similarly. In any case, the use of cost-benefit analysis is especially on those kinds of choices that have their results estimated regarding their money related qualities.

Nonetheless, most educational options are committed to upgrading accomplishment or some other result of education that are practically difficult to be transformed into financial terms. In these cases, those choices that have comparative objectives ought to be fixated on and analyzed through costviability analysis. In education, the point of cost-adequacy analysis is to figure out which program or a mix of projects can accomplish specific targets at the most minimal cost. The supposition behind this is that options of various types are related to various costs and distinctive educational outcomes. By picking those with the smallest expense for a given result, the general public can utilize its assets all the more successfully [23]. To that extent, cost-effectiveness becomes an alternative tool for the educational planner for the evaluation of educational programmes. Cost-effectiveness analysis is more appropriate for analyzing the non-economic benefits from education. According to Izuagba [17], costeffectiveness analysis measures non-economic alternatives in education, spillover benefits and externalities which are difficult to measure in monetary terms. It focuses on comparing educational inputs such as teachers, facilities, books, programmes etc. with such outputs as examination results, teacher retention, enrolment, completion rate etc.

The purpose of cost-effectiveness analysis in education is to determine the least cost alternative to achieving objectives. The basic assumption is that diverse alternatives are linked with different costs and different educational results. By deciding to adopt programmes with the least cost for a given output, a society can use its resources more efficiently. This is very essential because resources are scarce. Those resources that are saved through using more cost-effective methods can be dedicated to expanding programs or to other important educational activities. As an evaluation tool, costeffectiveness analysis is designed for assistance in the choice between alternative courses of action or policies, when resources are limited and, when educational decisions face constraints in the availability of budgetary processes and other resources.

Consequently, the limitation of evaluation on the educational consequences of alternatives alone without due consideration of their costs provides an ungrounded base for decision-making. The cost of some alternatives could be higher than others though yielding the same results, this entails that more resources must be sacrificed by the societies to achieve a given end. It is advisable to select those alternatives that are lower in cost to get at a particular objective or those with the greatest impact for any given investment as compared to a less cost-effective solution [24]. Educational planners can therefore use cost-effectiveness analysis when planning activities such as teacher training, teacher recruitment, choice of curriculum, computer-assisted instruction, determining class size etc.

\section{FINANCIAL CONSIDERATIONS IN EDUCATIONAL PLANNING}

A detailed analysis of the financial implications of a project is a major economic consideration in educational planning because finance constitutes a very significant factor in the success/failure of any educational plan. Budgetary allocation marks the single largest source of revenue to the education sector. A budget is an important economic instrument for facilitating and realizing the vision of a government in a fiscal year. It is a quantitative expression of a plan of action. The budget of a nation specifies the manpower, money, machines, and materials, i.e., the total resources of a country in utilization for different activities within a specific period. A budget is an important tool that enables educational planners to translate educational goals and objectives into action plans to ensure optimal efficiency.

The budgetary allocation available to educational planning in Nigeria is grossly inadequate, and this poses a big challenge to educational planning and national development. This situation is of grave concern to the stakeholders in education. 
Ileleji [25] observed that some planning departments in Nigerian's tertiary institutions rely on a monthly allocation of four thousand naira only, about twenty-six US dollars. Thus, inadequate funding is a great challenge to the planning unit of the educational sector to carry out any serious educational reform and innovation. Research grants are difficult to come by, attendance at conferences, workshops/ seminars receive very little attention. The education sector's inadequate funding has been one of the major factors militating against effective planning and implementation of educational programmes. For effective and adequate planning to enhance educational reform, there is the need for adequate financial resources to develop it.

The public education system in Nigeria is grossly underfunded and there are no mechanisms in place for improvement of its efficiency. For there to be progress, planning and budgeting must be improved and this cannot materialize so far as the ancient and inappropriate government financial and planning approaches and systems remain. For example, the efforts put in place to develop budgets are in most cases wasted during budget hearings by the legislature making the planners and the people to be disenfranchised and subject to last-minute arbitrary decisions. The more certain about the level of finance that will be available for a particular project; the easier it will be for the educational planner to translate realistically educational goals and objectives into programmes that will bring about significant changes in the systems.

\section{CONCLUSION}

Educational planning is a process that involves the application of rational and systematic analysis to the course of educational growth and development to make education more effective and efficient in responding to the needs and goals of society. Given present economic realities, there is a need to allocate resources efficiently and reduce wastage. This is a basis for the introduction of economics to educational planning. Seeing educational planning economically is imperative if productivity has to be the result of the huge investment made in education.

\section{SUGGESTIONS}

Based on the above discussion, the following suggestions were made:

1. The Federal Government of Nigeria should set up an institutional framework dedicated to the collection, collation, analysis, interpretation, and dissemination of labour market information to educational planners.

2. The Ministry of Education in collaboration with the National Bureau of Statistics should launch a strategic plan that will have the computing and provision of economic data necessary for educational planning as its focal point. Priority should also be given to the development of skills in data collection and analysis.

3. Specialists in educational planning and experts in other related fields should collectively put pressure on the government to help them see the extent of damage done to education as a result of underfunding.

\section{REFERENCES}

[1] UNESCO, Economic and social aspects of educational planning. Paris UNESCO, 1964

[2] Business Dictionary. (August 2020). Planning process. [Online]. Available: $\quad$ www.businessdictionary.com/definition/planningprocess.html.

[3] A.O. Alabi and T. Okemakinde, "Effective planning as a factor of educational reform and innovation in Nigeria", Current Research Journal of Social Sciences, vol. 2(6), pp. 316-321, 2010.

[4] K. K. Obasi, Economics of Educational Planning and National Development: Focus on Nigeria, Port Harcourt, Nigeria: Press, June 2020.

[5] N. P. Ololube, Educational management, planning and supervision: models for effective implementation, Owerri, Nigeria: SpringField, August 2013.

[6] A. Butt, Hussain, M. and S. Rehman (May 2016), Emergence of Educational Planning. [Online]. Available: https://www.slideshare.net/shafiqurrehman526/educational-planning56831868.

[7] K. D. Adaigbe. (June 2016). Educational planning in Ghana. [Online]. Available:

https://www.Researchgate.come.net/publication/3033310676educational-planning-in-Ghana.

[8] A. C. R. Wheeler, Essential economic concepts for educational planning, Paris: UNESCO, 1969.

[9] J. B. Babalola, Fundamentals of the economics of education, in basic text in educational planning. Ibadan: Department of Educational Management, J. B. Babalola Ed., pp. 127-191, 2015.

[10] S. Olowonefa and K. C. Orieaha, Educational administration and planning-concepts, theories and practice, Abuja, Nigeria: Immaculate Print, February 2016.

[11] A. O. Alao, "Revitalizing higher education through innovative labour market-based curriculum for sustainable national development," African Higher Education Review, vol. 8, pp. 49-54, January, 2014.

[12] National Bureau of Statistics. (February 2016), Employment Report. [Online]. Available: http://www.nigerianstat.gov.ng/report/397.

[13] M. Favara and I. Appasamy. Nigeria: skills for competitiveness and employability. Washington: World Bank, 2015.

[14] W. Kenton, (April 2020). Analysis of cost-benefit. [Online]. Available: investopedia.com/terms/cost-benefitanalysis.asp

[15] Smartsheet, (June 2020). An expert guide to cost-benefit analysis. [Online]. Available: smartsheet.com/expert-guide-cost-benefitanalysis\.

[16] M. Woodhall. Analysis of cost-benefit in educational planning $\left(4^{\text {th }} \mathrm{ed}\right)$ Paris: International Institute for Educational Planning, August 2004.

[17] N. J. Izuagba, "Cost of Education", In Economics of education: expository issues, J. M. Ebong, J. D. Asodike and N. J. Izuagba, Eds. Port Harcourt, Nigeria: EagleLithograph, pp. 160-182, 2016.

[18] J. M. Ebong, "Earning and School Quality," in Economics of education trends in Nigeria, P. J. M. Ebong and J. D. Asodike, Eds. Port Harcourt, Nigeria: EagleLithograph, pp. 43-60, 2016.

[19] O. O. Nelson. Principles and applications of educational policies in Nigeria. Port Harcourt, Nigeria: University Trust, May, 2010.

[20] S. C. Ihekweme, The economics of production, Owerri, Nigeria: Web media, 2013

[21] K. A. Achuonye, Trends in Nigerian Educational Innovations, Port Harcourt, Nigeria: Pearl. January 2008.

[22] C. C. Alabekee and E. U. Ugwumba, "Trends in Universal Basic Education in Nigeria", in Issues and trends in change and innovation in Nigerian educational system, J. O. Ajuonuma, J. D. Asodike and R. O. Anyaogu Eds., Port Harcourt, Nigeria: Pearl, pp. 101-110, 2015.

[23] H. M. Levin, "Cost-effectiveness Analysis", in International Encyclopedia of Economics (2nd ed.), M. Carnoy, Ed. Oxford: Perganon, pp. 381-386, October 1995.

[24] H. M. Levin, (2020). Cost effectiveness in education [Online]. Available: stateuniversity.com/pages/1887/Cost-Effectiveness-inEducation.html.

[25] O. O. Ileleji, "Educational planning in Nigeria: Strategies for improvement", African Journal of Geography and Regional Planning, Vol. 1, pp. 89-97, March 2014. 


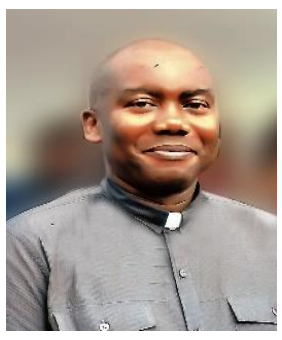

Kenneth K. Obasi was born in Mbaise, Imo State, Nigeria, he has ordained a Catholic Priest in 1996. The Rev Kenneth obtained two bachelors' degrees in Philosophy (1991) and Theology (1996) from Urban University, Rome In his quest for more academic exploits, he enrolled at Imo State University where he got his postgraduate diploma in education (PGDE) and subsequently switched over to the University of Port Harcourt where he obtained a postgraduate diploma in management sciences (PGDM), Masters (M.Ed.) and Doctor of Philosophy (Ph.D.) in Educational Management with Planning as his area of speciality. He also obtained a Masters' Degree in business management (MBA) with a bias in management.

Currently, he is a Reader at the University of Port Harcourt. He has published more than 50 articles in both local and international Journals. He belongs to some academic bodies such as the National Association for Educational Administration and Planning (NAEAP), Commonwealth Council for Educational Administration and Planning (CCEAP), Institute of Planning Nigeria (IPN).

Dr. Obasi is also a Certified Management Consultant (CMC) and so a Fellow of the Institute of Management Consultant (FIMC). To his credit, he is a London Graduate School Certified Management Specialist with Distinction in Time Management. Outside academics, the Reverend Obasi is a Nigerian Liaison Coordinator of the Amazing Grace Charismatic Prayer Ministry based in New Jersey, USA.

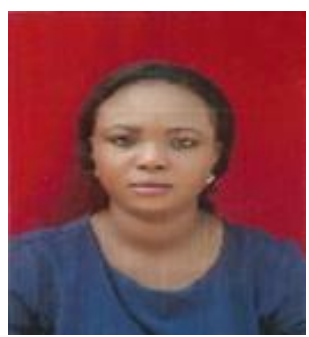

Sarah O. Osah was born in Benin City, Nigeria on the 9th of August 1987. In 2010, she obtained a Bachelor of Science (Education) in Economics and Statistics from the University of Benin, Benin City, Nigeria. She thereafter obtained a Master's degree in Educational Management and a Doctorate degree in Educational Planning from the University of Port Harcourt, Nigeria in 2016 and 2021, respectively. Her experience in education cuts across human resource management, administrative process and procedures, teacher recruitment and training, school leadership and management, school policy formulation, school mapping and plant planning.

She has been in the education space since 2010 having worked as a subject and classroom teacher before joining the British Council Nigeria exams operations team. In 2021 she founded Doyenlead Consulting, an organization on a mission to build better schools by offering administrative, recruitment, staff training and business advisory services. She has worked with many educational institutions to enhance their administrative, academic, and human resources processes for improved growth and performance.

Dr. Osah is a prolific researcher and writer and have had a number of her articles published in high impact journals. She has also attended many national and international conferences and has had the opportunity to present papers in some of these conferences. She is a member of the Nigerian Association for Educational Administration and Planning (NAEAP). 